\title{
Mixed Migraine and Tension-type: A Common Cause of Recurrent Headache in Children
}

\author{
Shashi S. Seshia
}

\begin{abstract}
Objective: Determine relative frequency of recurrent headache (HA) types in children and adolescents referred to a pediatric neurologist. Methods and subjects: Study design: Prospective, sequential, and observational. Setting: Private practice Pediatric Neurology Clinic in a Canadian city (Winnipeg). Patients and data collection: Information on those referred with HA between September 1998 and December 2001 was entered on data sheets. Patients were followed up for one month to four years. Results: Three hundred and twenty (69\%) of 463 referred with HAhad recurrent HA. There were 172 males (54\%) and 148 (46\%) females. Their ages ranged from two years to 19 years (median: 11 years). They had had their HA disorder for one month to 14 years (median: two years) prior to assessment. Migraine was the main HA type in $124(38 \%)$, tension-type headache (TTH) in $57(18 \%)$ and mixed migraine and TTH in 101 (32\%). Thus, 101 (45\%) of 225 with migraine as one HAtype also had TTH. Conclusions: Tension-type headache and migraine frequently co-exist and may represent a distinct headache type, at least in children; the association will likely influence response of affected children and adolescents to specific migraine treatments in clinical trials or practice.
\end{abstract}

\begin{abstract}
RÉSUMÉ: Céphalée mixte de type migraineux et de tension: une cause fréquente de céphalée récurrente chez les enfants. Objectif: Déterminer la fréquence relative des différents types de céphalées récurrentes chez les enfants et les adolescents référés en neuropédiatrie. Méthodes et sujets: Il s'agit d'une étude prospective d'observation de cas successifs référés à une clinique de neurologie pédiatrique privée à Winnipeg, Canada. Les données ont été recueillies chez les patients référés pour céphalée de septembre 1998 à décembre 2001. La durée du suivi variait de 1 mois à 4 ans. Résultats: Trois cent vingt (69\%) des 463 patients référés pour céphalée présentaient des céphalées récurrentes, dont 172 garçons (54\%) et 148 (46\%) filles, âgés de 2 à 19 ans (médiane: 11 ans). Ils souffraient de céphalée depuis 1 mois à 14 ans (médiane: 2 ans). Le principal type de céphalée était la migraine chez 124 patients (38\%), la céphalée de tension chez 57 (18\%) et la céphalée mixte de type migraineux et de tension chez $101(32 \%)$. Ainsi, 101 (45\%) des 225 patients migraineux avaient également des céphalées de tension. Conclusions: La céphalée de tension et la migraine coexistent fréquemment et représentent peut-être un type distinct de céphalée, du moins chez les enfants. Dans les études de pharmacologie clinique et en pratique clinique, cette association influence probablement la réponse au traitement spécifique de la migraine chez ces enfants et ces adolescents.
\end{abstract}

Can. J. Neurol. Sci. 2004; 31: 315-318

The ad hoc Committee on Classification of Headache ${ }^{1}$ recognized an entity of mixed migraine and tension-type headache (TTH), a category excluded from the 1988 International Headache Society (IHS) classification. ${ }^{2}$ The IHS classification, ${ }^{2}$ which has just been revised, ${ }^{3}$ has been adopted by pediatric neurologists, modifications being suggested to make the criteria better applicable to children and adolescents (hereafter referred to collectively as children). ${ }^{4-8}$ The World Health Organization has listed effective prevention and treatment of headache in children as a priority. ${ }^{9}$ An understanding of headache types that children experience is a prerequisite to such a step.

This paper, therefore, reports on headache types in 320 children with recurrent headache.

\section{MATERIALAND METHODS}

These are identical to those in a companion paper. (Chronic Daily Headache in Children and Adolescents)

\section{Patients and setting}

The data on children referred primarily with headache to the Pediatric Neurology Clinic at the Manitoba Clinic, Winnipeg,

Presented at the 38th Meeting of the Canadian Congress of Neurological Sciences, June 17-21, 2003, Quebec City, Canada

From the Manitoba Clinic, Winnipeg, MB, Canada.

ReCEIVED MAY 26, 2003. ACCEPTED INFINALFORM NOVEMBER 27, 2003.

Reprint requests to: S.S. Seshia, Division of Pediatric Neurology, Royal University Hospital, 103, Hospital Drive, Saskatoon, SK. 7N 0W8 Canada. 
were entered on standardized data sheets. Children and guardians were interviewed together and children were then interviewed separately. They were instructed to keep a headache calendar prospectively and follow-up appointments were made. They were asked to provide descriptions for each headache type. Frequency was recorded for individual days and separately for day and night. Severity was graded on a numerical pain scale which they were familiar with.

\section{Study design and study period}

Data were collected prospectively and sequentially from September 1998 to December 2001.

\section{Excluded population}

Those in whom headache was not the presenting complaint but in whom a history of headache may have been obtained "on inquiry" were excluded.

\section{Definitions and classification}

Recurrent headache was defined as the occurrence of headache for less than 15 days a month, regardless of duration of individual headache episodes. Headaches were classified according to the IHS classification, ${ }^{2}$ the criteria for migraine without aura being modified for children. ${ }^{6,7}$ Headaches were subtyped to the 1st, 2 nd or 3rd digit level of the IHS classification. ${ }^{2}$ For example, migraine coded as 1 is a diagnosis at the 1 st digit level. Migraine without aura coded as 1.1 is a diagnosis at the 2 nd digit level. In this paper, TTH refers to episodic TTH (code 2.1) and "headache of the TT not fulfilling above criteria" (code 2.3).

Children who described discrete episodes of migraine and TTH or headaches fulfilling criteria for migraine and TTH at different stages of the same attack were considered to have "mixed" migraine and TTH.

\section{Statistical analyses}

Fisher's Exact Test was used to determine significance between groups.

\section{RESULTS}

\section{General data}

Four hundred and sixty-three children were referred with headache during the study period. Of these, 143 (31\%) had chronic daily headache and are excluded from further discussion.

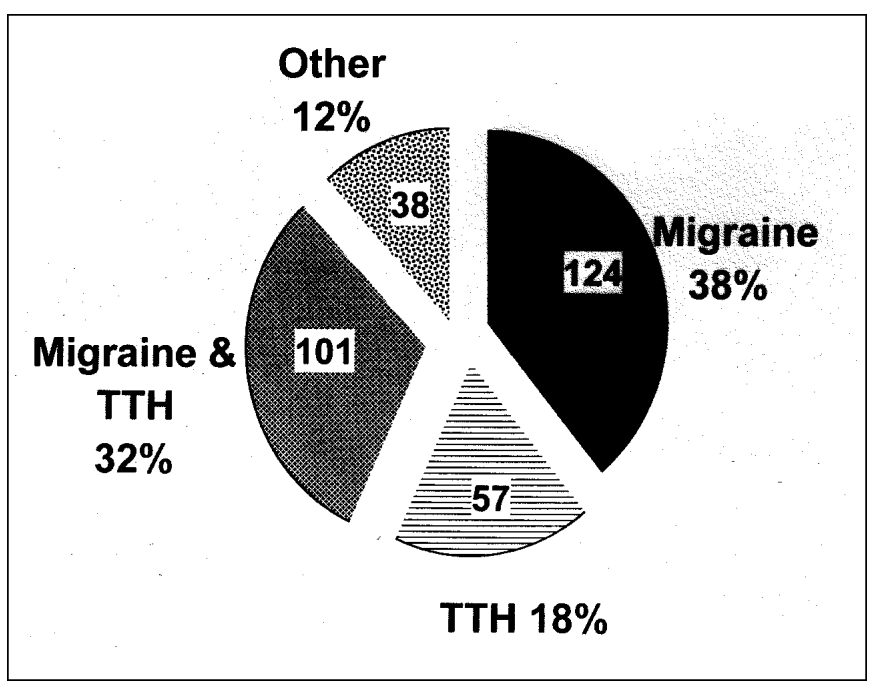

Figure: Distribution of diagnostic headache categories

The remaining $320(69 \%)$ of the 463 children had recurrent headache. The duration of the headache disorder ranged from one month to 14 years (median: two years). A family history of headache in 1st or 2nd degree relatives (parents, siblings, grandparents, uncles or aunts) was obtained in $75 \%$.

\section{Gender and age}

There were 172 males (54\%) and 148 females (46\%). The difference is marginally significant $(\mathrm{p}=0.03)$. The females ranged in age from two years to 19 years with a median of 11 years and modal of 12 years. The males ranged in age from three years to 18 years with both median and modal ages of 10 years.

\section{Main diagnostic categories (Figure; Table 1)}

Two hundred and eight two of the $320(88 \%)$ were classified into one of three categories: migraine was the main headache diagnosis in 124 children (38\%) and TTH in 57 (18\%); 101 (32\%) experienced both migraine and TTH (mixed). Thus, almost half $(45 \%)$ of the 225 children with migraine as one headache type, also had TTH.

One child with migraine also had cluster headache. Three children classified as migraine developed the disorder after

Table 1: Main Headache Categories (Diagnosis) $(\mathrm{N}=282)$

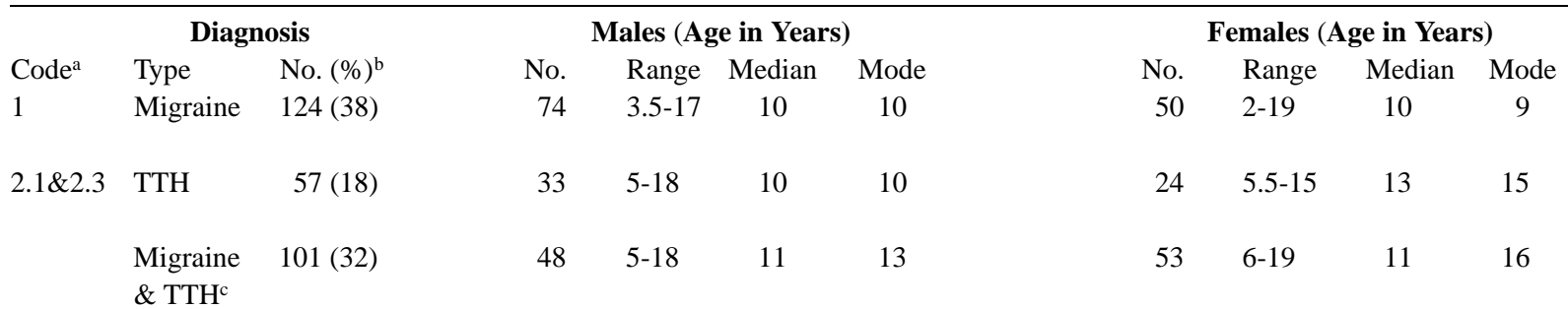

Total

282

155

127

${ }^{\mathrm{a}}$ International Headache Society (IHS) Code for headache type ${ }^{2} ;{ }^{\mathrm{b}} \%$ of $320 .{ }^{\mathrm{c}}$ There is no Code because the IHS ${ }^{2}$ does not recognize a mixed category; TTH=tension-type headache 
minor concussion and would have been classified by IHS criteria under Group 5 (headache associated with head trauma) rather than under Group 1 (migraine), as would have another child who developed mixed migraine and TTH after concussion. One child with a VP shunt developed headaches of the TT; shunt malfunction was ultimately excluded and she was classified as having TTH.

There was no significant difference in age (range, median and modal) or gender distribution between the three categories.

\section{Other diagnoses $(\mathrm{N}=38 ; 12 \%$ of 320 ; Table 2$)$}

The headaches in 17 children (5\%) could not be classified because of inadequate description. All three children with postconcussion (post-traumatic) headache had features of TTH.

Three children had space-occupying lesions. One of them had headaches clinically fulfilling the criteria for migraine without aura; his neurological examination was normal; $80 \%$ of his attacks occurred in the morning after awakening, a reason for ordering a CT scan. The remaining two seemed to have short paroxysms (lasting seconds or minutes) of headache with crying and holding the head; one of them had paroxysms worse in the morning and during physical activity. One of the two had papilledema and ataxia; the neurological examination was normal in the other. The headaches in the child with aneurysm of the vein of Galen could not be classified clinically because of inadequate description; his neurological examination was normal.

\section{Other features}

Three children were diagnosed with an anxiety disorder (one: migraine; one: TTH; one: mixed) and four with depression (three with TTH and one with migraine).

Seventy-five percent of those with migraine experienced vomiting within five minutes to 60 minutes of headache or aura onset.

\section{Neuroradiology}

Computed tomography scans were done in 57 (18\%) and were abnormal in four (7\%); three of the four had spaceoccupying lesions and one had an aneurysm of the vein of Galen. An MRI scan was done in two patients: one had an incidental

\section{Table 2: Other Diagnostic Categories $(\mathrm{N}=38)$}

\begin{tabular}{llr}
\hline Code* $^{*}$ & Diagnosis & No. \\
13 & Not classifiable & 17 \\
4.5 & Benign exertional headache & 4 \\
7.6 & Space occupying lesion & 3 \\
5.2 .2 & Minor head trauma & 3 \\
11.5 & Sinusitis/respiratory infection & 3 \\
1.5 .1 & Benign paroxysmal vertigo of childhood with headache & 2 \\
4.1 & Idiopathic stabbing headache & 2 \\
3 & Cluster headache & 1 \\
6.4 & Arteriovenous venous malformation & 1 \\
12 & Cranial neuralgia & 1 \\
12.1 .6 & Neck tongue syndrome & 1 \\
& Total & $\mathbf{3 8}$
\end{tabular}

* IHS Code ${ }^{2}$; ages, gender and percentages are not provided because numbers are small. lesion and the other was for better definition of a spaceoccupying lesion. Additionally, MRI scans with MR angiography were done in $10(3 \%)$ and were normal in all.

\section{Follow-up, treatment and outcome}

Twenty-five ( $8 \%$ ) of the 320 were lost to follow-up, despite telephone reminders. Twenty of the 25 had had normal CTscans. The remaining 295 were followed up for periods of one month to four years (median: six months), typically until headaches were not considered to be a problem for child and family. One child with a space-occupying lesion died; excluding those with spaceoccupying lesion/arteriovenous venous malformation $(\mathrm{N}=4)$ and those lost to follow-up ( $\mathrm{N}=25), 288$ of the remaining 291 were greatly improved; $232(80 \%)$ improved without specific treatment other than suggestions for prevention, nonmedication methods (such as using ear plugs if noise was a trigger or sun glasses when the sun was a trigger) and the occasional use of analgesics. One child with migraine developed benign rolandic epilepsy in the course of follow-up.

\section{Discussion}

"Headache is the most common indisposition of mankind", ${ }^{10}$ a statement as true for children as for adults. Sillanpaa and AbuArafeh ${ }^{11}$ cite several references to show that the prevalence of "overall" headache in children has increased over three fold from about $23 \%$ to $71 \%$ and of migraine three fold from $1.9 \%$ to $5.7 \%$ between the 1970s and 1990s; some of the increase may be due to improved ascertainment of childhood headache and the influence of the IHS classification. ${ }^{2}$ They suggested that the increase was more marked in boys than in girls, an opinion supported by the slightly greater frequency of males in the current study. The author is unaware of any Canadian data on this subject.

In the present study, $124(38 \%)$ had migraine, $57(18 \%)$ had TTH and 101 (32\%) had both (mixed) migraine and TTH. The children with mixed migraine and TTH could be readily separated from those who had migraine or TTH alone, since they experienced headache attacks fulfilling the current requirements for the definition of both migraine and TTH respectively. The association between migraine and TTH may be due to chance or reflect a bias of diagnosis. However, a number of investigators have argued for a continuum or co-existence of migraine and TTH in children and adults. ${ }^{5,6,12-18}$ Stang and Von Korff ${ }^{19}$ found mixed forms of migraine to be common among primary care headache patients but the responsible physicians usually recorded a single diagnosis of either migraine or TTH. Lipton et $\mathrm{al}^{20}$ also favored the hypothesis that among adult migraineurs, episodic TTH and migraine "are part of a single pathophysiologic continuum". In their study, sumatriptan was effective for both migraine and TTH in migraineurs. ${ }^{20}$ Sumatriptan is ineffective for episodic TTH alone. ${ }^{21}$ The frequent association between $\mathrm{TTH}$ and migraine is now acknowledged by the IHS. ${ }^{3}$ Hence, there are clinical reasons to re-instate the entity of a mixed migraine and TTH type in headache classification.

One child with a space-occupying lesion had headaches that fulfilled the clinical criteria for migraine without aura. Forsyth and Posner ${ }^{22}$ emphasized the nonspecific nature of brain tumor headache. Several patients in their study had headaches that clinically met IHS criteria for TTH or migraine without aura. We 
previously reported on a child who was found to have slit ventricle syndrome and shunt malfunction whose headaches fulfilled the clinical requirements for migraine without aura. ${ }^{8}$ One must, therefore, clearly distinguish between types of headache and etiologies of headache, since any primary headache type may be clinically mimicked by an organic cause.

My study was not designed to assess the role of neuroimaging in children with recurrent headache. Most of the $57 \mathrm{CT}$ scans done in this study were ordered by referring physicians. Magnetic resonance imaging (with MR angiography) scans were performed when there was a family history of aneurysm, if headache was occipitally located or when headache was consistently worsened with physical activity. The Quality Standards Subcommittee of the American Academy of Neurology and the Practice Committee of the Child Neurology Society ${ }^{23}$ advised that the routine use of any diagnostic study was unnecessary when there were no associated risk factors in the history and the child's examination was normal.

The majority of children in the current study improved without specific treatment. However, the study was not designed to assess treatment options in an evidenced-based manner. PrysePhillips et $\mathrm{al}^{24,25}$ provided evidenced-based guidelines for the management of migraine in adults. A similar approach was attempted for children. ${ }^{26}$

My study has selection biases common to studies on subjects with headache. Frequently, children are inadequate historians. 5,27 None provided detailed written descriptions of headache attacks and the author was the only clinician involved. However, the use of standardized data sheets and standardized definitions should minimize the potential for variability. In an earlier study, there was complete agreement at the 1 st or 2 nd digit level between my clinical diagnosis of headache types and the IHS diagnosis assigned by an independent physician in 29 out of 30 cases. ${ }^{5}$ As in other studies, the relative incidences of headache types and diagnoses in the current study will be influenced by referral bias and cannot be applied to the general population.

Biases notwithstanding, my study supports the existence of a relatively common and distinct primary headache disorder with features of both migraine and TTH in children referred to a pediatric neurologist. Population studies are needed to establish the incidence of this type, the recognition of which has important implications for clinical trials and management.

\section{ACKNOWLEDGEMENTS}

The author thanks the Manitoba Clinic for help with chart retrieval and the Children's Research Foundation of Manitoba Inc., for financial support. The author thanks Mr. Don Cates for statistical analysis; and Drs. Victor Chernick, Dawn Hartfield, Molly Seshia, Bryan Young and Jerry Yager for reviewing drafts of the manuscript.

\section{Disclosure}

The author has received honoraria from GlaxoSmithKline for speaking at three meetings organized by the company.

\section{REFERENCES}

1. Ad hoc Committee on Classification of Headache. Arch Neurol $1962 ; 6: 13-16$

2. Classification Committee of the International Headache Society. Classification and diagnostic criteria for headache disorders, cranial neuralgias and facial pain. Cephalalgia 1988; 8 (suppl 7):1-96.

3. Headache Classification Subcomittee of the International Headache
Society. The International Classification of Headache Disorders. 2nd ed. Cephalagia 2004;24 (suppl 1): 1-152.

4. Mortimer MJ, Kay J, Jaron A. Epidemiology of headache and childhood migraine in an urban general practice using Ad hoc, Vahlquist and IHS criteria. Dev Med Child Neurol 1992; 34:1095-1101.

5. Seshia SS, Wolstein JR, Adams C, Booth FA, Reggin JD. International Headache Society criteria and childhood headache. Dev Med Child Neurol 1994;36: 419-428.

6. Seshia SS, Wolstein JR. International Headache Society Classification and diagnostic criteria in children: a proposal for revision. Dev Med Child Neurol 1995;37:879-882.

7. Winner P, Martinez W, Mate L, Bello L. Classification of Pediatric Migraine: proposed revisions to the IHS Criteria. Headache 1995;35:407-410.

8. Seshia SS. Specificity of IHS Criteria in childhood headache. Headache 1996;36:295-299.

9. World Health Organization. Headache disorders and Public Health. WHO/MSD/MBD/00.9. Geneva: World Health Organization 2000:1-8.

10. Barlow C. Headaches and migraine in childhood. Clinics in Developmental Medicine No. 91. Oxford: Spastics International Medical Publications, 1984:1.

11. Sillanpaa M, Abu-Arafeh I. Epidemiology of recurrent headache in children. In: Abu-Arafeh I, (Ed.) Childhood Headache. Clinics in Developmental Medicine No. 158. London: Mac Keith Press 2002:19-34.

12. Gladstein J. Episodic tension-type. In: Abu-Arafeh I, (Ed.) Childhood Headache. Clinics in Developmental Medicine No. 158. London: Mac Keith Press 2002:96-100.

13. Waters WE. The epidemiology enigma of migraine. Int J Epidemiol 1973;2: 189-194.

14. Hockaday J. Definitions, clinical features, and diagnosis of childhood migraine. In: Hockaday J, (Ed.) Migraine in Childhood. London: Butterworth 1988; 5-24.

15. Rossi LN, Cortinovis I, Bellettini G, Brunelli G, Bossi A. Diagnostic criteria for migraine and psychogenic headache in children. Dev Med Child Neurol 1992; 34:516-523.

16. Viswanathan V, Bridges SJ, Whitehouse W, Newton RW. Childhood headaches: discrete entities or continuum? Dev Med Child Neurol 1998; 40: 544-550.

17. Rossi LN, Cortinovis I, Menegazzo L, et al. Classification criteria and distinction between migraine and tension-type headache in children. Dev Med Child Neurol 2001; 43:45-51.

18. Couch CR, Verhulst SJ, Stewart KE, Samuel SR, Leviston CL. Primary headache as a spectrum disorder. Cephalagia 2001; 21:262.

19. Stang PE, von Korff M. The diagnosis of headache in primary care: factors in the agreement of clinical and standardized diagnoses. Headache 1994; 34:138-142.

20. Lipton RB, Stewart WF, Cady R, et al. Sumatriptan for the range of headaches in migraine sufferers: results of the spectrum study. Headache 2000; 40:783-791.

21. Brennum J, Brinck T, Schriver L, et al. Sumatriptan has no clinically relevant effect in the treatment of episodic tension-type headache. Eur J Neurol 1996;3:23-28.

22. Forsyth PA, Posner JB. Headaches in patients with brain tumors: a study of 111 patients. Neurology 1993; 43:1678-1683.

23. Lewis DW, Ashwal S, Dahl G, et al. Report of the quality standards subcommittee of the American Academy of Neurology and the Practice Committee of the Child Neurology Society. Practice Parameter: evaluation of children and adolescents with recurrent headaches. Neurology 2002; 59:490-498.

24. Pryse-Phillips WEM, Dodick DW, Edmeads JG, et al. Guidelines for the diagnosis and management of migraine in clinical practice. Can Med Assoc J 1997; 156:1273-1287.

25. Pryse-Phillips WEM, Dodick DW, Edmeads JG, et al. Guidelines for the nonpharmacologic management of migraine in clinical practice. Can Med Assoc J 1998; 159: 47-54.

26. Seshia SS. My head hurts: headaches in children. Can J CME 1999; 11:119-135.

27. Koenig MA, Gladstein J, McCarter RJ, et al. Chronic daily headache in children and adolescents presenting to tertiary headache clinics. Headache 2002;42:491-500. 